\title{
Análisis de contenido en mensajes impresos sobre enfermedades de transmisión vectorial en un municipio de Colombia
}

Content analysis in printed messages about vector-borne diseases in a municipality in Colombia

Luz Mary Ortiz Guerrero ${ }^{1}$, Lina María Carreño Parra ${ }^{2}$, Marco Antonio Márquez Gómez ${ }^{3}$

\section{Resumen}

Las enfermedades de transmisión vectorial (ETV), como dengue, zika y chikungunya, representan un problema de salud pública en Colombia. Autoridades e instituciones de salud municipales promovieron campañas de prevención y manejo de los factores asociados a estas enfermedades. no obstante, el municipio de Ocaña registró una alta prevalencia. Se realizó un análisis de contenido a 14 mensajes comunicativos impresos orientados a la prevención de enfermedades de transmisión vectorial durante el período de 2014 a junio de 2016. Las unidades de análisis comprendieron términos referidos a la enfermedad, términos generales, partes del texto (frases y oraciones) y función y objetivo de la imagen, bajo los constructos control y prevención de ETV con los códigos de vector, enfermedad y público. Se emplearon como instrumentos de recolección y análisis de datos los siguientes: instrumento de evaluación de material educativo de la OPS, instrumento específico adhoc para evaluación de contenido y la prueba objetiva INFLESZ. Si bien, el grado de legibilidad de las unidades comunicativas fue de 'normal' hasta 'muy fácil', se identificaron oportunidades de mejora para la comprensión e identificación del público meta, necesarios para la educación en salud, que no genere interpretaciones contrapuestas desde los aspectos semióticos y semánticos sobre conductas y comportamientos, y sobre todo, que

\footnotetext{
1. Comunicadora social. Grupo de investigación Tecnnosalud, Universidad Nacional Abierta y a Distancia, Colombia. ORCID: https://orcid.org/0000-0001-7079-4713

2. Fisioterapeuta, comunicadora social. Grupo de investigación Fisura, Universidad Nacional Abierta y a Distancia, Colombia. ORCID: https://orcid.org/0000-0001-8220-4151

3. Químico Farmacéutico. Grupo de investigación Tecnnosalud, Universidad Nacional Abierta y a Distancia, Colombia ORCID: https://orcid.org/0000-0002-4181-8963 
se perciba como un mensaje que va dirigido a un público específico, con la exigencia de contextualización frente a los lineamientos generales y la participación de la comunidad.

Palabras claves: Enfermedad transmisible, salud pública, comunicación persuasiva, impacto de la comunicación, comunicación en salud, Colombia

\section{Abstract}

Vector-borne diseases (VTD), such as dengue, zika and chikungunya, represent a public health problem in Colombia. Municipal authorities and health institutions promoted campaigns to prevent and manage the factors associated with these diseases. However, the municipality of Ocaña registered a high prevalence. A content analysis was carried out on 14 printed communicative messages aimed at preventing vector-borne diseases during the period from 2014 to June 2016. The analysis units included terms referring to the disease, general terms, parts of the text (phrases and sentences) and function and objective of the image, under the control and prevention constructs of VTD with the vector, disease and public codes. The following instruments were used as data collection and analysis instruments: PAHO educational material evaluation instrument, ad-hoc specific instrument for content evaluation and the INFLESZ objective test. Although the legibility of the communicative units was from 'normal' to 'very easy', opportunities for improvement were identified for the understanding and identification of the target audience, necessary for health education, which does not generate conflicting interpretations from the semiotic and semantic aspects about behaviors and behaviors, and above all, that it is perceived as a message that is addressed to a specific audience, with the requirement of contextualization in front of the general guidelines and community participation.

Keywords: Transmitted diseases, public health, persuasive communication, impact of communication, health communication, Colombia. 


\section{Introducción}

En todo el mundo se registran cada año más de 1000 millones de casos y más de 1 millón de defunciones como consecuencia de las enfermedades de transmisión vectorial (ETV). Estas enfermedades representan más del 17\% de todas las enfermedades infecciosas y su propagación está determinada por una compleja dinámica de factores medioambientales y sociales (1).

En Colombia, el Plan Decenal de Salud Pública 2012 - 2021 señaló que dichas enfermedades representan una elevada carga social y económica en la población en riesgo e identificaron las de mayor interés en salud pública para el control, la vigilancia y la prevención, siendo éstas: la enfermedad de Chagas, dengue, leishmaniosis, malaria, chikungunya y zika. Dada la situación de propagación de enfermedades transmitidas por vectores en lo que va corrido de esta década, se pusieron en marcha unos lineamientos para el control de ETV que se acogen a la Estrategia de Gestión Integrada (EGI) para la promoción en salud, prevención y control, 2012-2021, donde el mismo Ministerio, el Instituto Nacional de Salud y entidades Municipales de Salud, unificaron sus esfuerzos para el control, vigilancia y prevención de dichas enfermedades (2).

El dengue, el chikungunya y el zika son enfermedades virales que se transmiten por la picadura de la hembra del mosquito Aedes aegypti que se reproduce en agua limpia. El dengue y el zika se producen por arbovirus del género flavivirus de la familia Flaviviridae, el chikungunya, por su parte, es un virus ARN del género alfavirus de la familia Togaviridae. Estos virus se replican en las células del mosquito transmisor, favoreciendo la infección de las células epiteliales de su intestino; luego, las partículas virales producidas en estas células son liberadas al hemocele y hacia algunos órganos del mosquito, como las glándulas salivares, las cuales se convierten en órganos reservorios para el virus (3).

En el territorio colombiano existen diferentes factores de riesgo para la transmisión de ETV, los cuales se encuentran relacionados con determinantes dinámicos como la intensificación de la migración interna, conflicto armado, cultivos ilícitos, violencia, pobreza en zonas rurales, crecimiento desordenado de los núcleos urbanos, la explotación de los bosques y metales preciosos (uso del suelo), las secuelas ambientales de proyectos estatales y privados, una deficiente gestión del ambiente, además del pobre liderazgo de las entidades territoriales de salud para identificar e intervenir oportunamente los brotes de cada enfermedad (4).

En el municipio de Ocańa entre el 2014 y 2016, de acuerdo con el Sistema de Vigilancia Epidemiológica Municipal (SIVIGILA), las ETV representaron un problema de salud registrando casos nuevos y una alta prevalencia, habiéndose identificado entre ellos el dengue, el chikungunya y el zika. En el ańo 2015, sobre el zika se conocieron 4 casos con un extremo aumento a 342 
en el 2016; en el caso de chikungunya, en el 2014 fueron 16 los casos y para el 2015 la cifra subió a un total de 146; situación contraria, aunque no deja de ser preocupante, sucedió con el dengue, presentando en 2014 con 704 casos y para 2015 con 494, pese a las campańas comunicacionales sobre prevención y manejo de los factores asociados a estas enfermedades.

La Organización Mundial de la Salud (OMS) define el concepto de comunicación en salud como el uso de estrategias que permiten informar e influenciar decisiones individuales y comunitarias que mejoren la salud. Puede contribuir en todos los aspectos de la prevención de la enfermedad incluyendo la relación médico-paciente, la adherencia del individuo a recomendaciones clínicas y regímenes terapéuticos, la construcción de mensajes y campañas de salud pública en conjunto con la diseminación de información concerniente a riesgos para los individuos y las poblaciones, o comunicación preventiva (5).

Un estudio exploratorio de carácter descriptivo de casos específicos en la ciudad de Bogotá D.C., se aproximó a la situación de la comunicación en los programas de promoción y prevención de la salud sobre las estrategias implementadas por la Secretaría Distrital de Salud, las Entidades Promotoras de Salud (EPS) y los medios de comunicación para la divulgación de los programas, quienes concluyeron que la práctica comunicativa en y para la salud se ha centrado en la elaboración de productos con información bajo el modelo médico y, aunque se viene trabajando en la comunicación en cuestiones de promoción de la salud y prevención de la enfermedad, los vacíos existentes en esta temática en el país se hace evidente (6).

Por otro lado, una investigación desarrollada durante los años 2007 al 2009 (7), en el que se realizó un análisis de contenido para determinar la representación de la obesidad en la prensa, determinó el buen manejo de la información con señalamientos importantes en la necesidad de seguir este camino, "en esa oportunidad que se tiene para realizar investigación sobre periodismo y salud pública desde la academia por medio de análisis de contenidos hasta de discursos o desde los medios de comunicación por medio del periodismo investigativo, repensar la comunicación en y para la salud en su fin de promover cambios y transformaciones culturales para el cuidado en salud, la relación de la práctica comunicativa con el contexto doméstico, local, regional y nacional y los aspectos y factores que identifican a la comunidad, pues las patologías traen más consecuencias a la salud, que termina generando una complejidad patológica, de ahí que el cuidado en la información es esencial desde las diferentes perspectivas".

Estas manifestaciones, ponen de relieve a la comunicación en salud concebida en la interacción transformadora que implica la coordinación de los procesos de cambio en las estructuras mentales, relacionando en la comunicación con ideas de organización y conocimiento, no reducidos meramente a 
los productos comunicativos, sino que involucra el acto comunicativo en un contexto determinado, que ponen en común una información, ideas, emociones, habilidades mediante palabras, imágenes (8). O según otro autor (9), todo acto de comunicación entabla su base en la conducta simbólica que tiene lugar de acuerdo a las acciones humanas, lo que conlleva a la producción, intercambio y reconstrucción de sentidos y significados, que en su conjunto exige la dinámica activa hacia ese pragmatismo social desde los conceptos lingüísticos y semióticos, para la acción en favor de la salud. En este punto, "el lenguaje es una conducta simbólica, entendiéndolo no solo desde un punto de vista gramatical y sintáctico sino también desde un punto de vista pragmático".

Por ello, resulta fundamental la comprensión de los modelos comunicacionales de cambio con prioridad a las audiencias en aspectos específicos como la prevención y el control de las ETV, algunos de los cuales se aprecian en la Tabla 1, para el impacto en los mismos factores estructurales, culturales, sociales y psicológicos que influencian en la conducta y los diferentes determinantes que pueden generar cambios en los comportamientos (10).

Tabla 1. Teorías de Cambio de la Comunicación para la Salud según Choque (8)*

\begin{tabular}{|c|c|c|}
\hline Modelo y Categorías & Modelos del nivel individual & Modelos del nivel comunitario \\
\hline Teorías & $\begin{array}{l}\text { - Teoría de las Etapas del Cambio } \\
\text { - Teoría de Creencias en Salud } \\
\text { - Teoría de Acción Razonada }\end{array}$ & $\begin{array}{l}\text { - Teoría del Aprendizaje Social } \\
\text { - Teoría de Difusión de Innovaciones } \\
\text { - Teoría del Mercadeo Social }\end{array}$ \\
\hline Postulados & $\begin{array}{l}\text { - El individuo es el elemento más importante para } \\
\text { proporcionar cambios de comportamiento } \\
\text { - Creencias, actitudes, comportamientos y conductas } \\
\text { individuales } \\
\text { - El cambio del comportamiento es un proceso y no un acto }\end{array}$ & $\begin{array}{l}\text { - Permiten comprender como funcionan y cambian los sistemas } \\
\text { sociales } \\
\text { - Se ajustan a estrategias integrales de promoción de la salud a } \\
\text { nivel comunitario } \\
\text { - Estimulan el bienestar comunitario mediante estructuras y } \\
\text { políticas que promueven un estilo de vida saludable }\end{array}$ \\
\hline Convergencia & $\begin{array}{l}\text { - Permiten la comprensión de la conducta humana frente a } \\
\text { temas relacionados con la salud y sus determinantes a nivel } \\
\text { individual } \\
\text { - Analizan la dinámica del comportamiento de acuerdo a las } \\
\text { influencias externas, determinando el proceso para cambiarlo }\end{array}$ & $\begin{array}{l}\text { - Permiten la comprensión de la conducta humana frente a } \\
\text { temas relacionados con la salud y sus determinantes a nivel } \\
\text { comunitario } \\
\text { - Identifican los métodos más adecuados en los programas para } \\
\text { lograr cambios en los resultados }\end{array}$ \\
\hline Divergencia & $\begin{array}{l}\text { - Disposición individual del cambio hacia comportamientos } \\
\text { saludables } \\
\text { - Percepciones individuales sobre las amenazas que puede } \\
\text { causar un problema de salud } \\
\text { - Evaluación individual del comportamiento para prevenir un } \\
\text { problema de salud, adoptando conductas saludables }\end{array}$ & $\begin{array}{l}\text { - Influencia de pensamientos, ejemplos, consejos y ayudas } \\
\text { frente al comportamiento en los temas de salud } \\
\text { - Difusión de prácticas, estilos e ideas dentro de una sociedad y } \\
\text { de esta a otra con el fin de adoptar métodos de prevención } \\
\text { - Análisis, planificación, ejecución y evaluación de programas } \\
\text { con el fin de mejorar el bienestar social }\end{array}$ \\
\hline
\end{tabular}

* Se agrupan en Modelos de nivel individual y Modelos de nivel comunitario.

Fuente: Adaptación de los autores a partir de Choque 2005. 
Así, la presente investigación consideró el enfoque teórico del mercadeo social con aplicación de sus técnicas, permitiendo el análisis y conocimiento ordenado y sistematizado del producto social a promover (la salud), la comunidad (audiencia o grupo meta a abordar) y las diferentes variables que median entre éstos dos (factores individuales, colectivos, ambientales y culturales), para diseñar mensajes, seleccionar medios de difusión, divulgar mensajes y controlar y evaluar el impacto de los mismos que reforzarán los hábitos y los comportamientos saludables, con el objetivo de analizar la oferta de un producto o idea social hacia cambio social favorable $(11,12)$.

Desde la perspectiva comunicacional, se reivindica el contenido como parte de este análisis desde lo semántico y lo semiótico y, se convierte en el dispositivo como un acto de acción transformadora; así, se vincula al desarrollo de la idea de autonomía moral de los pacientes -o en este caso, de la población en su conjunto- para tomar decisiones (13).

El contenido se revela en el tipo de material comunicativo, muchas veces un problema frecuente, pues generalmente es aislada su producción frente a los objetivos y técnicas de un programa educativo definido, quizás en la adopción de las acciones de acuerdo a lineamientos nacionales sin determinar elementos y características del contexto social y el público meta al momento de su producción, por lo que resulta importante la elección del mismo. Aquí se enfatiza en el material comunicativo escrito, cuyo contenido contempla datos textuales y no textuales, demandando conocer esa relación del conjunto de características tipográficas y lingüísticas del texto escrito que permiten leerlo y comprenderlo con facilidad (codificación - decodificación) como de las imágenes que admiten representatividad e identificación; que en conjuntos constituyen indicadores clave de calidad en la producción de material comunicativo.

De esta manera, con una situación preocupante, vacíos existentes sobre esta temática y la reciente consideración frente a la salud como pilar de la Agenda 2030 para el Desarrollo Sostenible, surgió el interrogante sobre ¿cuáles fueron los contenidos de los mensajes impresos de interés en salud pública orientados en la prevención de enfermedades transmitidas por vectores en el municipio de Ocaña durante los años 2014 a 2016?, estableciéndose como inferencias las siguientes: 1. Los mensajes impresos son desarrollados a partir de lineamientos y/o enviados desde el Ministerio, faltando representatividad de la realidad del municipio. 2. Los mensajes impresos son usados de manera aislada; además, poco responden en relación a la facilitación de acciones con respecto a lo que el municipio oferta. 3. Los mensajes impresos son poco reconocidos en la práctica como elemento fundamental en las estrategias de educación y comunicación para la construcción de red de acciones significantes para las dos dimensiones que constituyen el ser humano (emisor-receptor): la identidad individual y la sociedad. 


\section{Materiales y métodos}

La investigación consideró el método de análisis de contenido desde el enfoque cualitativo descriptivo y el modelo deductivo-inductivo. El universo recayó en 24 unidades comunicativas a las que se tuvo acceso sin entablar diferencia en el tipo de producción que contemplaron el dengue, chikungunya y zika, publicadas y/o emitidas en el periodo de tiempo que generó las alarmas en salud pública frente a dichas patologías en el municipio. Se les asignó un código y se construyó una matriz con el fin de caracterizarlas, poniendo en consideración categorías como: código de identificación; tipo de producción, carácter, público meta, nivel de abordaje, año de emisión - periodo de tiempo definido para la investigación.

Con esta caracterización se puntualizó la muestra de las unidades a conveniencia, tomándose como decisión que fueran las de tipo de producción impreso, para un total de 14. Las razones obedecieron a lo siguiente:

- Mayor número de unidades de comunicación a las que se tuvo acceso según el tipo de producción sobre el tema de interés; más aún, con mayor disponibilidad en las diferentes estrategias comunicativas, indiferente del nivel de abordaje en salud.

- La delimitación del tema a analizar, para tratarlos en un único proceso de análisis de contenido, con la pretensión de controlar de alguna manera resultados divergentes y dificultades en el establecimiento de las categorías y sus relaciones, siendo este tema considerado desde el tipo de producción.

-La implicación de los elementos presentes en el corpus de contenido, seleccionando las más pertinentes.

La muestra se descompuso en las partes denominándose unidad de análisis, representadas en los términos referidos a la enfermedad, términos generales, partes del texto (frases y oraciones) y función y objetivo de la imagen, bajo los constructos de control y prevención de ETV con los códigos de vector, enfermedad y público, con base en el modelo comunicacional de cambio de mercadeo social hacia la influencia para aceptar, rechazar, modificar o abandonar algún comportamiento para el beneficio del individuo, del grupo o de la sociedad. Ver Tabla 2. 
Tabla 2. Panorama general apuesta metodológica específica para la investigación.

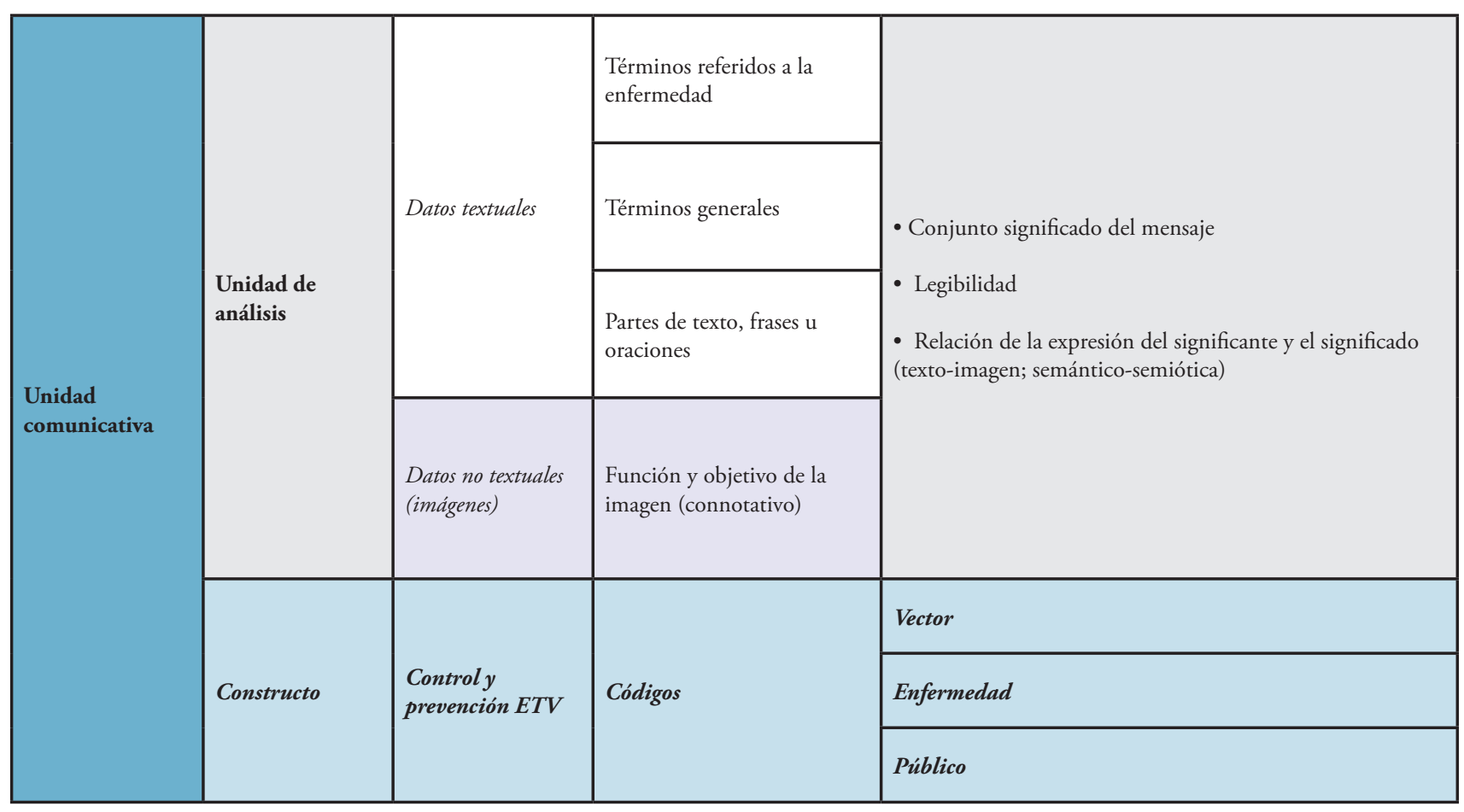

Fuente: Construcción de los autores.

Se procedió a la evaluación de las unidades comunicativas utilizando inicialmente dos instrumentos de evaluación de material educativo recomendados por la Organización Panamericana de la Salud (14). Uno de ellos, Pauta de evaluación de criterios generales para todo tipo de material, el cual contempla 12 criterios propuestos: participación de la población blanco del material educativo, representa situaciones de la vida diaria, forma parte de un programa educativo, disponibilidad de los servicios o recursos que promueven, dispone de otros materiales o técnicas que refuerzan el mensaje, sometimiento a un pre-test de estos materiales, consta de instructivos para su utilización, si se tuvo en cuenta caracterización de la población a quién se dirige el material edu- cativo, mensaje respetuoso incluyente, se evidencia participación del equipo interdisciplinario, respeta en su mensaje la libertad de decisión, responde a un objetivo específico. En él se indica si el material educativo cumple o no con los criterios generales y se emite el número de criterios cumplidos con el comentario si se da el caso por parte de los expertos. El otro es Pauta para evaluación de material impreso, el cual cuenta con nueve criterios propuestos: tema específico, mensaje comprensible, ilustraciones, tamańo de la letra, elementos de síntesis, elementos que resaltan ideas importantes, gramática, información concreta y lenguaje acorde a la comunidad. Utiliza una escala de Likert de 1 a 5, calificando de acuerdo con el grado de cumplimiento, 5 corresponde a un cum- 
plimiento total y 1 indica incumplimiento, los cuales se suman al final para finalmente decidir según la siguiente escala: usar como está ( 40 - 45 puntos), necesita reformas (21 - 39) y rechazado (menos de 20 puntos) y los comentarios de los expertos.

Por otro lado, se diseñó y elaboró un instrumento con el fin de contemplar la ficha técnica de los mensajes impresos y, obtener mayor comprensión sobre los criterios que evalúan los instrumentos de la OPS, para el caso particular de los mensajes impresos, siendo este de carácter subjetivo. Este instrumento contempló nueve criterios propuestos en preguntas abiertas $y$, adicionalmente, las primeras siete con respuesta dicotómica SI o NO, con la intención de recoger aquellos datos que permitieran describir e interpretar el contenido complementario a los resultados generados por los instrumentos de la OPS bajo las categorías de la semántica y semiótica.

Adicionalmente, se aplicó una técnica objetiva para el análisis de la legibilidad lingüística denominada Escala INFLESZ para evaluar la legibilidad de los textos dirigidos a pacientes, la cual está validada y establece en una escala de medición tipo Likert (15).

Estos instrumentos fueron enviados a un panel población - expertos, conformado por dos profesionales del sector de la salud, uno de ellos con estudio posgradual en salud pública y el otro con experticia en atención en salud sobre el fomento y cuidado en salud y atención primaria con el desarrollo de espacios educativos y comunicativos y todos con experiencia docente universitaria; dos comunicadoras sociales, una docente universitaria con formación en el sector de la salud y experiencia en salud pública y educación y comunicación en salud y, a su vez comunicadora social y la otra en formación con opción de grado; y siete personas de la población del municipio, en quienes se distribuyó las unidades comunicativas.

\section{Análisis y discusión}

El material impreso es el producto más empleado en las diferentes campañas y en todos los niveles de abordaje y de atención en salud, estos se consideran como unidades más de carácter informativo y, en contadas ocasiones como mecanismos de control, por ende, su utilidad como insumo complementario en campańas, planes, programas, entre otros, son de vital importancia, aunque en la práctica opera con uso más aislado.

Frente a la recopilación total de mensajes publicitarios de interés en salud pública relacionado con el tema abordado, se tuvo acceso a 24 productos comunicativos, detallados en la tabla 3, sobre los cuales se realizó un pre-análisis, de los cuales 16 correspondían al tipo de producción escrito o impreso, 12 eran de carácter informativo y considerados 21 de ellos en el nivel de abordaje masivo. 
Tabla 3. Matriz de caracterización de los 24 productos comunicativos.

\begin{tabular}{|c|c|c|}
\hline \multirow{4}{*}{ Caracterización } & Tipo producto & Cantidad \\
\hline \multirow{4}{*}{ Tipo de reproducción } & Audiovisual & 4 \\
\cline { 2 - 3 } & Audio & 16 \\
\cline { 2 - 3 } & Escrito & 16 \\
\hline \multirow{3}{*}{$\begin{array}{c}\text { Carácter de los } \\
\text { mensajes }\end{array}$} & Dengue & 11 \\
\cline { 2 - 3 } & Chikungunya & 10 \\
\cline { 2 - 3 } & Zika & 15 \\
\cline { 2 - 3 } & Informativo & 12 \\
\hline \multirow{3}{*}{ Nivel de los mensajes } & Educativo & 8 \\
\cline { 2 - 3 } & Comunicativo & 5 \\
\cline { 2 - 3 } & Individual & 9 \\
\hline & Comunitario & 21 \\
\hline
\end{tabular}

Fuente: Construcción de los autores.

Se analizaron 14 de 16 unidades comunicativas totales, dos fueron descartadas pues hacían referencia a procesos de educación en salud mediante talleres educativos. Estas unidades abordaron las tres ETV prevalentes en el municipio de Ocaña, 10 de estas tenían el carácter informativo, 13 fueron consideradas para un nivel de abordaje masivo y la totalidad de estas unidades no consideraron segmentación de público.

Posteriormente, desde el constructo se analizó la perspectiva de información, predominando en las 14 unidades información sobre signos de alarma de la enfermedad, manejo clínico de la enfermedad y sobre las acciones de prevención y control del vector.
Con estos aspectos pre-analizados, se prosiguió con los criterios generales o esas cualidades deseables para todo tipo de material contemplados por el instrumento de la OPS, hallándose que las preguntas "1¿participó la audiencia a quien va dirigido en la selección, elaboración y evaluación del material?", "6 - ¿han sido sometidos a prueba antes de su elaboración final?” y "7 - ¿constan de instructivos para su utilización?”, fueron las que presentaron en el corpus de las unidades según los diferentes evaluadores como las de menos cumplimiento, aspectos que son relevantes pues los sujetos de la audiencia o público son los focos de acción de los procesos comunicativos a quien se le dirige la información para la producción de sentidos. 
Sobre los criterios específicos o las cualidades características para el material impreso, arrojó como resultado que 12 de las unidades estuvieron en el grado de cumplimiento entre 21 y 39 puntos, es decir, "necesita reformas" $y$, dos de ellas estuvieron en el rango de cumplimiento de 40 a 45 puntos, con la decisión que se puede "usar como está". Se halló que el criterio 3 que señala si "las ilustraciones aclaran o complementan lo escrito" era el de más bajo cumplimiento.
Otro aspecto que es importante resaltar es que los evaluadores no coincidieron en algunos criterios, por lo que la interpretación de la evaluación hace evidente la diferencia para la decisión final, como sucedió con las unidades comunicativas identificadas con los números 9, 15, 18 y 21, que para algunos se podría "usar como está", mientras para otros "necesita reformas". Ver Tabla 4.

Tabla 4. Base de datos de la información recolectada.

\begin{tabular}{|c|c|c|c|c|}
\hline Idemat. & Evaluador & $\begin{array}{l}\text { Criterios Generales } \\
\text { No. Criterios cumplidos }\end{array}$ & $\begin{array}{l}\text { Criterios material } \\
\text { Impreso/decisión }\end{array}$ & $\begin{array}{l}\text { Grado de legibilidad en la } \\
\text { Escala de Inflesz }\end{array}$ \\
\hline \multirow{3}{*}{9} & 3 & 7 & Necesita reformas & \multirow{3}{*}{ Normal } \\
\hline & 8 & 6 & Usar como está & \\
\hline & 9 & 6 & Usar como está & \\
\hline \multirow{3}{*}{15} & 1 & 8 & Usar como está & \multirow{3}{*}{ Bastante Fácil } \\
\hline & 8 & 3 & Necesita reformas & \\
\hline & 9 & 0 & Necesita reformas & \\
\hline \multirow{3}{*}{17} & 6 & 7 & Necesita reformas & \multirow{3}{*}{ Algo difícil } \\
\hline & 8 & 5 & Necesita reformas & \\
\hline & 9 & 5 & Necesita reformas & \\
\hline \multirow{3}{*}{18} & 5 & 7 & Usar como está & \multirow{3}{*}{ Muy fácil } \\
\hline & 8 & 2 & Necesita reformas & \\
\hline & 9 & 2 & Necesita reformas & \\
\hline \multirow{3}{*}{21} & 4 & 7 & Usar como está & \multirow{3}{*}{ Bastante fácil } \\
\hline & 8 & 6 & Usar como está & \\
\hline & 9 & 7 & Necesita reformas & \\
\hline
\end{tabular}

Fuente: Construcción de los autores a partir de algunos de los datos recolectados durante la investigación.

Desde otro punto de vista, con la medición objetiva de legibilidad de los datos textuales, se encontró que 13 unidades permiten su lectura y comprensión con re- sultados entre "bastante fácil” y "normal”, cuyo Índice Flesch-Szigriszt estuvieron en los rangos de 62,36 a 76,9 y 58,69 a 63,54 respectivamente; excepto la unidad comu- 
nicativa 17 cuyo índice es de 51, 6 como "algo difícil".

Si se relaciona la evaluación con los criterios contemplados por los instrumentos de la OPS frente a la prueba objetiva de índice de Inflesz, deja en evidencia que no necesariamente coincidan sus resultados para finalmente dar uso de este material. Entonces, se pone en consideración esa relación que se establece de la semántica y la semiótica para la comprensión, aceptación e identificación de los mensajes contenidos, que finalmente requieren ser valorados antes de hacer público este tipo de materiales comunicativos.

Uno de los elementos que se busca en la identificación con lo que el contenido divulga y de manera particular en el constructo establecido de control y prevención en los códigos definidos sobre el vector, la enfermedad y el público, se encuentra en la semántica lingüística (significante). En este se permite decodificar la información en el objeto o concepto que trae el sujeto o público a quien se le dirige el mensaje, es decir, a través del significante se traslada el mensaje a quien va a recibir la comunicación, lo que puede llegar a constituirse en barrera para la identificación y reconocimiento del sujeto y su comunidad si la producción de estos materiales parte desde una dirección o como es el caso de estas unidades comunicativas que siguieron unos lineamientos nacionales sin la debida contextualización en su territorio.

En algunas de las unidades comunicativas estudiadas, los aspectos textuales fueron la utilización de algunos términos o palabras como "auto medicarse PUEDE SER MORTAL", "quiero vivir y... no morir por dengue", interpretadas como alarmantes y de muerte, como se puede observar en la unidad comunicativa 10 (Imagen 1).

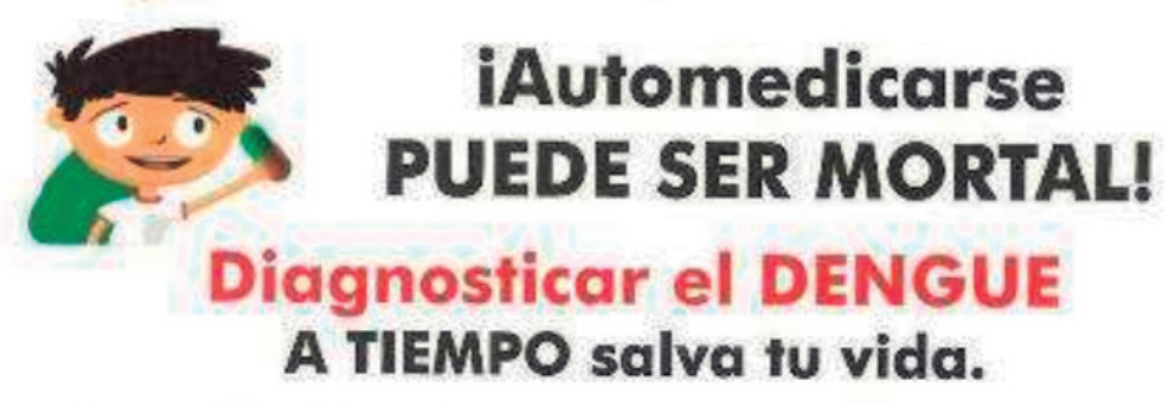

Si presenta fiebre dos o más de los siguientes síntomas como Dolor de Cabeza, Malestar General, Dolor Articular Dolor detrás de los Ojos

Fuente: Suministrada por la institución origen. 
Además, esta unidad es controvertida frente al uso de imágenes y su relación en el mensaje, llamando la atención que sea un menor de edad frente a datos textuales cuyas responsabilidades implica un mayor conocimiento y madurez o le son propias a los adultos. Esta controversia fue identificada en otra unidad con la utilización de un término como "auto medicarse" frente a la imagen de un menor y en las unidades $12 \mathrm{y}$ 13 con la imagen de un animal "perro", que toma la vocería del experto que maneja la información cuya connotación cuestiona la función y objetivo de la imagen (ver Imagen 2).

Imagen 2. Unidad comunicativa 12.

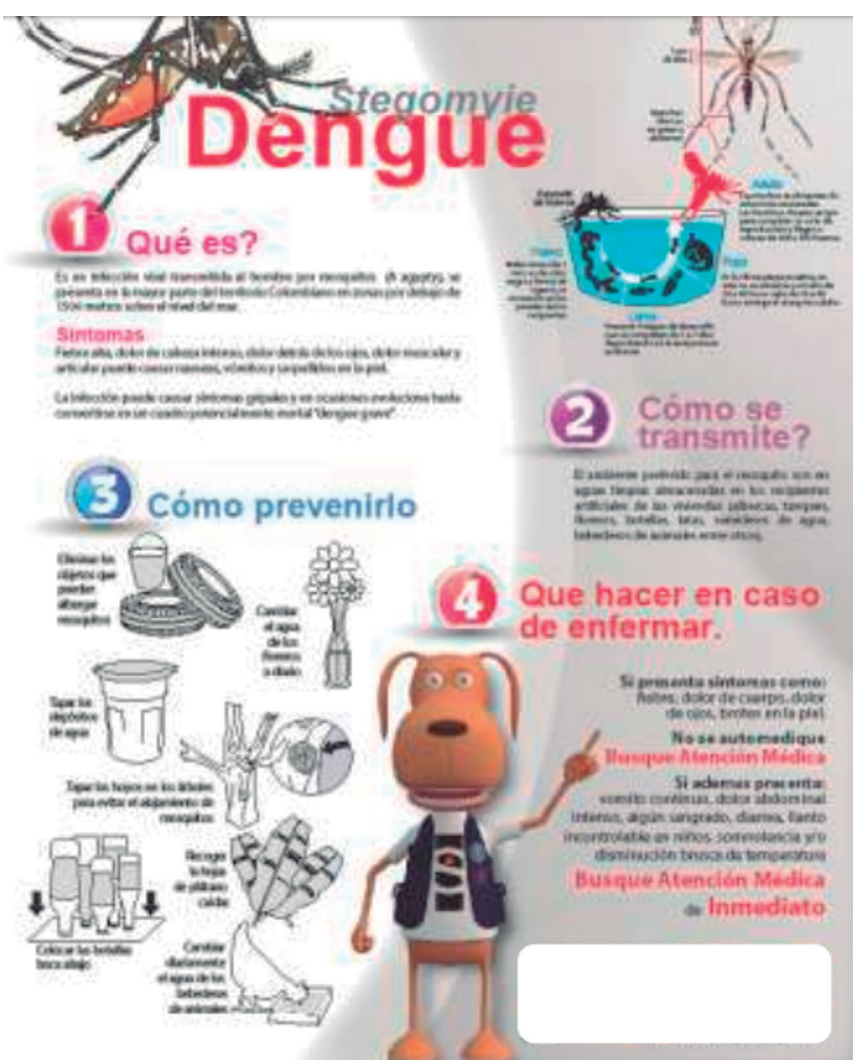

Fuente. Suministrada por la institución origen.

Si bien es cierto, estos recursos publicitarios textuales o no textuales se disponen en la producción de mensajes en favor de los códigos poéticos o estéticos y de la creatividad, en los aspectos relacionados con salud que pretende formar ciudadanos empoderados en el cuidado de la salud y la vida misma, su función no es la de crear belleza, es persuadir frente a una idea concreta en un contexto y momentos dados; es decir, los códigos que funcionan en toda la multidimensionalidad de la comunicación que se expresa en este tipo de productos publicitarios, más que en otros, debe guardar una proporcionalidad en la presentación del mensaje, pues en esta práctica se requiere 
el empoderamiento en esa formación ciudadana para el cuidado mismo de la salud y la vida.

En esas expresiones y uso de imágenes, para los evaluadores correspondientes a los códigos del 1 al 9 de la población general, consideraron que eran ofensivas para su comunidad, lo que llevó a la consideración que la distribución del contenido del mensaje resalta poco lo que se quiere. Estos reparos pueden ser comprendidos, en esa necesidad de un derecho a la información que le permita identificarse, que le sea representativa en el mensaje y, no le genere más interpretaciones que lo que se pretende. Es decir, requiere que el objetivo del mensaje sea claro, que le permita despertar y mantener la atención sobre dicho mensaje al individuo, al colectivo y a la comunidad, replanteando en primera instancia que lo atractivo del mensaje publicitario para esta situación, requiere de información suficiente.

Otro aspecto analizado del contenido basado en la semántica lógica (significado) buscaba la representatividad, que en un primer momento de decodificación del mensaje con la recolección de información, algunos mensajes representaron un "toque fuerte" a la significación que le proporcionaba dicho contenido, considerando que contenía elementos ofensivos, como en las unidades comunicativas $10,11,12,15$ y 18 , pues la información transmite el sentimiento de temor y alarmas que podrían desbordarse, generando una mala interpretación de lo que es el cuidado en salud y distorsión en lo que podría ser la indicación sobre una acción preventiva: "quiero vivir y no morir por dengue" (unidad comunicativa 18).

Expresiones similares fueron señaladas en relación con la unidad comunicativa 11 , en el que se destacó la situación alarmante, no dejando en claro, si se deseaba destacar la acción preventiva o sólo informar de la situación de salud urgente que se presentaba en el municipio.

La explicación ante estos aspectos se da en el manejo de una información general 'completa' en material impreso de carácter informativo, que podría comprenderse en la saturación de la misma, que distrae y resta atención a su contenido, y por ende, a la no aceptación del mismo.

En ese sentido, desde la semántica lógica, con base en el constructo y los códigos, los enunciados cobran mucha importancia para la construcción del mensaje, pues en esa intencionalidad de la publicidad de interés en salud pública para la contribución en el empoderamiento y su movilización hacia el control y prevención de las ETV (constructo de la presente investigación), la precisión de los conceptos conlleva a acciones más efectivas y eficaces de los individuos y las comunidades sobre la variable de control comprendida desde la promoción.

Con base en lo expuesto, no se identificó un contexto informativo establecido desde 
la perspectiva comunicacional bajo la comprensión de la multidimensionalidad, multifactorialidad e intersectorialidad de una realidad social presente: identificación de la región en sus acciones, conductas, comportamientos y recursos como en la oferta de las mismas instituciones, quedando la información del mensaje bajo el discurso médico del seguimiento, el control y vigilancia de unas "enfermedades" (ETV) que implica "muerte" como en esa atención de la información epidemiológica.

Este es uno de los aspectos que considera la Teoría del Mercadeo Social, pues al considerar las técnicas propias del mercadeo comercial (análisis, planificación, ejecución y evaluación), condiciona elementos clave para su desarrollo denominadas variables controlables de mercadeo que se cruzan con las variables de análisis de mercadeo, variables que desde el análisis de contenido como método y como técnica, reclama como pertinente para la aplicación e implementación del constructo en un mensaje comunicativo cuya alcance es la persuasión hacia cambios y la toma de decisiones y no en el aspecto de la mera información para que se tenga un conocimiento $(11,16)$.

Así, los aspectos relacionados con la semántica cognitiva (referente), establece que cada mensaje debe cumplir un objetivo específico dentro de un programa estructurado mediante estrategias que forme parte de un plan de acción, para la generación de una formación frente a los ser- vicios ofertados en el municipio, más allá de la existencia una institución que se hace responsable de una vigilancia y, más en el trabajo conjunto del control y prevención.

Desde este análisis, se encuentra la complejidad de esa red léxica que se construye en relación al constructo y sus códigos planteados para este proyecto; es decir, su propio campo semántico, que no se comprende tanto en que se comparte un núcleo de significación o rasgo semántico común, pero sí se diferencian por otra serie de rasgos semánticos en una perspectiva cognitiva que permiten hacer distinciones, en este sentido, se demuestra la urgencia sobre la comprensión de los alcances e implicaciones de los conceptos de control y prevención y, en términos de producción, la necesidad de segmentación del público.

Si bien fueron evidentes los esfuerzos para el control y prevención de las ETV por parte de los responsables en el municipio de Ocaña, las estrategias comunicativas fueron frágiles, pues fueron empleados de manera aislada y poco responden a la facilitación de acciones que el municipio oferta frente al control y prevención de las ETV.

En este sentido, la identificación de un contexto informativo desde la perspectiva comunicacional bajo la comprensión de la multidimensionalidad, multifactorialidad e intersectorialidad de una realidad social presente poco fue estimada: identificación de la región en sus acciones, conductas, 
comportamientos y recursos como en la oferta de las mismas instituciones, quedando la información del mensaje bajo el discurso médico del seguimiento, el control y vigilancia de unas "enfermedades" (ETV) que implica "muerte" como en esa atención de la información epidemiológica.

Este es uno de los aspectos que, considera la Teoría del Mercadeo Social, pues la aplicación del mercadeo social al considerar las técnicas propias del mercadeo comercial (análisis, planificación, ejecución y evaluación), condiciona elementos clave para su desarrollo denominadas variables controlables de mercadeo que se cruzan con las variables de análisis de mercadeo (11), variables que desde el análisis de contenido como método y como técnica, reclama como pertinente para la aplicación e implementación del constructo en un mensaje cuyo alcance es la persuasión hacia cambios y la toma de decisiones y no en el aspecto de la mera información para que se tenga un conocimiento.

Este corpus de mensajes analizados requiere modificaciones en sus contenidos y estrategias acompañantes a los lineamientos nacionales, que permiten comprender unos datos textuales y no textuales, frente a la intencionalidad comunicativa que debe ser transversalizada por el control y prevención de las ETV y, no viceversa, para ser comprendida y reconocida -desde los materiales comunicativos impresos-, como red de acciones significantes para las dos dimensiones que constituyen el ser hu- mano (emisor-receptor): la identidad individual y la sociedad.

\section{Conclusiones}

A partir de esta investigación, se comprende que en el análisis de contenidos de los mensajes comunicativos impresos de interés en salud pública, surge la necesidad de establecer más estudios y trabajos acuciosos donde se tengan presente estos métodos y técnicas de investigación, que permitan un acercamiento mayor en términos de representatividad, identificación y aceptación final en la producción de materiales comunicativos, lo que implica comprender que la comunicación tiene mayores alcances sobre la transformación social en favor de la población que comparte un territorio cotidianamente.

El reconocimiento de los individuos y su comunidad se hace necesario para la presentación del mensaje, de lo que allí se expone a quienes se espera se modifique las estructuras mentales de conocimiento, las conductas y comportamientos, lo que exige la identificación del contexto informativo de las unidades comunicativas. Con ello, se hace necesario que desde la producción de materiales comunicativos se tenga presente las teorías del cambio, que aquí se sugiere como la más recomendada para la publicidad de interés en salud pública la del Mercadeo Social, clave para desarrollar planes y estrategias que generen escenarios favorables, creando conciencia sobre un tema, logrando la aceptación de una con- 
ducta deseada y modificando el comportamiento que produzca un beneficio ya sea individual o comunitario con los recursos disponibles presentes en el contexto. Adicionalmente, recobra importancia un principio de los materiales educativos-comunicativos seńalado por la OPS en 1984, "los materiales son parte de un programa educativo, pero no son el programa mismo".

Por otra parte, se hace visible, desde lo comunicacional, el juego de la pre-producción-pos de los productos comunicativos con el empleo de unos recursos publicitarios: no sólo debe establecer un constructo en un área temática, del conocimiento o del saber, sino el establecimiento de unos códigos sobre ese constructo, que favorece la precisión del mensaje, aspectos fundamentales en la comunicación en salud, en el que se persuade ante el suministro de elementos de juicio a una persona o comunidad/sociedad, hacia cambios conductuales y comportamentales en favor de la salud y su cuidado.

Finalmente, se establece la importancia de unas condiciones diferenciadoras en los procesos comunicativos en salud para conseguir efectos de cambios en el cuidado de la salud en cualquier momento del territorio $\mathrm{y}$, mayores respuestas efectivas ante las emergencias.

\section{Agradecimientos}

Los autores agradecen a la Universidad Nacional Abierta y a Distancia; a la en- fermera Lendy Andrea Escalante Angarita, coordinadora de Vigilancia Epidemiológica del municipio de Ocańa; y a las instituciones prestadoras de servicios de salud del municipio de Ocańa, por todo el apoyo y cooperación recibida para la realización de este trabajo.

\section{Referencias}

1. Organización Mundial de la Salud. Enfermedades transmitidas por vectores. Nota descriptiva No. 387. Centro de Prensa. 2016. Disponible en: http://www. who.int/mediacentre/factsheets/fs387/es/

2. Colombia. Ministerio de Salud y Protección Social. Resolución No. 1841 de 2013. Por la cual se adopta el Plan Decenal de Salud Pública 2012 - 2021. Imprenta Nacional de Colombia, Bogotá D.C.; 2013. Disponible en: https://www.minsalud.gov.co/sites/ rid/Lists/BibliotecaDigital/RIDE/DE/DIJ/resolucion-1841-de-2013.pdf

3. Kantor Isabel N. Dengue, Zika y Chikungunya. Medicina (B. Aires). 2016; 76(2): 93-97. Disponible en: http://www.scielo.org.ar/scielo.php?script=sci_ arttext\&pid=S0025-76802016000200006\&lng=es

4. Colombia, Ministerio de Salud y Protección Social. Malaria - Memorias. Bogotá. 2013. Disponible en: https://www.minsalud.gov.co/sites/rid/Lists/BibliotecaDigital/RIDE/VS/TH/memorias_malaria.pdf

5. Ríos Hernández Iván. Comunicación en salud: conceptos y modelos teóricos. Revista perspectivas de la comunicación. 2011; 4(1): 123-140. Disponible en: http://revistas.ufro.cl/ojs/index.php/perspectivas/ article/view/111

6. Torres Montero, V.A y Chaves Cabrera, R.A. La comunicación en los programas de promoción y prevención de la salud en Bogotá: secretaría distrital de salud, EPS y medios de comunicación. 2008. Pontificia Universidad Javeriana, Bogotá. Disponible en: 
https://www.javeriana.edu.co/biblos/tesis/comunicacion/tesis39.pdf

7. Carmona Blanco, V. La obesidad como problema de salud pública y su representación en el periódico El Tiempo (2007 al 2009). 2009. Pontificia Universidad Javeriana, Bogotá. Disponible en: https:// www.javeriana.edu.co/biblos/tesis/comunicacion/ tesis303.pdf

8. Choque Laurrari, R. Comunicación y educación para la promoción de la salud. 2005. Lima. Disponible en: http://www.razonypalabra.org.mx/libros/ libros/comyedusalud.pdf

9. Aguado, J.M. Introducción a las teorías de la comunicación y la información. 2004. Murcia. Disponible en: https://www.um.es/tic/Txtguia/Introduccion $\% 20$ a $\% 20$ las $\% 20$ Teorias $\% 20$ de $\% 20$ a $\% 20$ Informa $\% 20(20) /$ TIC $\% 20$ texto $\% 20$ guia $\% 20 \mathrm{com}$ pleto.pdf

10. Mosquera, M. Comunicación en Salud: Conceptos, Teorías y Experiencias. 2003. Disponible en: http:// www.portalcomunicacion.com/obregon/pdf/Mosquera_2003.pdf

11. Forero Santos, J. El marketing social como estrategia para la promoción de la salud. Revista electrónica La sociología en sus escenarios. [Internet]. 2009; 20: 1-23. Disponible en: https://aprendeenlinea.udea.edu.co/revistas/index.php/ceo/article/ view/7021/6440

12. Castro, M., Gómez, X., Monestel, P. y Poveda, K. Mercadeo Social en Salud: conceptos, principios y herramientas. 2014. San José, Costa Rica. Disponible en: http://www.fao.org/fileadmin/user_upload/ red-icean/docs/Mercadeo $\% 20$ Social\%20en \%20 Salud\%20PDF.pdf

13. López Noguero. El análisis de contenido como método de investigación. XXI. Revista de Educación. 2002. 4, 167-179. Disponible en: http://rabida.uhu.es/dspace/bitstream/handle/10272/1912/ b15150434.pdf?sequence 1
14. Organización Panamericana de la Salud. Guía para el diseño, utilización y evaluación de material educativo en salud No. 10. En Serie PALTEX para técnicos, medios y auxiliares (1-73). 1984. Disponible en: http://www.fmed.uba.ar/depto/edunutri/ 2015guia.pdf

15. Barrio-Cantalejo I.M., Simón-Lorda P., Melguizo M., Escalona I., Marijuán M.I., Hernando P. Validación de la Escala INFLESZ para evaluar la legibilidad de los textos dirigidos a pacientes. Anales Sis San Navarra [Internet]. 2008 Ago; 31(2): 135-152. Disponible en: http://scielo.isciii.es/scielo.php?scrip$\mathrm{t}=$ sci_arttext $\&$ pid $=$ S1 137-66272008000300004\&1ng=es

16. Pereira Palacio, J., Gaviria Mejía, L., Zea-Castrillón, S., Jaramillo Arbleáez, P., \& Bedoya, A. (2018). Descripción de pruebas moleculares en el diagnóstico del virus Zika en el periodo 2008-Febrero 2018. Revisión sistemática. NOVA, 16(30), 81-93. Disponible en: https://revistas.unicolmayor.edu.co/index. $\mathrm{php} /$ nova/article/view/872 